\title{
Review
}

\section{The Risk for Infant Mortality among Adolescent Childbearing Groups}

\author{
MAUREEN G. PHIPPS, M.D., M.P.H., ${ }^{1}$ MARYFRAN SOWERS, Ph.D., ${ }^{2}$ \\ and SONYA M. DEMONNER, M.P.H. ${ }^{3}$
}

\begin{abstract}
Objective: To evaluate risk disparities and risk factors for infant mortality among adolescent childbearing age groups.

Methods: We combined the 1995 and 1996 comprehensive U.S. birth cohorts provided by the National Center for Heath Statistics. Our analysis included 777,762 singleton, first births to women aged 12-19 years linked to 4631 infant deaths. We used both bivariate comparisons and multivariable logistic regression for our analysis, with infant mortality as our main outcome measure.

Results: Rates of infant mortality are substantially higher for $\leq 15$-year-olds $\mathbf{( 8 . 1 / 1 0 0 0}$ live births) compared with 16-17-year-olds (6.3/1000 live births) and 18-19-year-olds (5.4/1000 live births). Even after adjusting for risk factors associated with poor outcomes, including alcohol use, tobacco use, and prenatal care use, the risk for infant mortality was 1.6 (95\% confidence interval $[95 \% \mathrm{CI}] \mathbf{1 . 4}, 1.7)$ times greater for infants of mothers $\leq 15$ years old as compared with those mothers 18-19 years old. In the $\leq 15$-year-old group, $62 \%$ of fathers were not reported on the child's birth certificate. Not reporting the father was associated with a $24 \%$ increased risk for infant mortality after adjusting for maternal and infant risk factors.

Conclusions: Childbearing in $\leq 15$-year-olds is associated with a substantial increased risk for infant mortality compared with childbearing in older adolescence. This study suggests that not reporting the father on a birth certificate is a potential risk marker. Risk differences among adolescent age groups may be important to consider when creating tailored intervention and prevention strategies.
\end{abstract}

\footnotetext{
${ }^{1}$ Brown Medical School, Women \& Infant Hospital of Rhode Island, Department of Obstetrics and Gynecology, Providence, Rhode Island.

${ }^{2}$ University of Michigan School of Public Health, Department of Epidemiology and Department of Obstetrics and Gynecology, Ann Arbor, Michigan.

${ }^{3}$ University of Michigan Robert Wood Johnson Clinical Scholars Program and VA Center for Practice Management and Outcomes Research, Ann Arbor, Michigan.

M.G.P. conducted this research as a fellow in the Robert Wood Johnson Scholars Program at the University of Michigan.
} 


\section{INTRODUCTION}

A DOLESCENT CHILDBEARING has been associated with increased risks for poor birth outcomes, including preterm delivery, low birth weight, and infant mortality. ${ }^{1-4}$ Causes for the poorer birth outcomes in adolescents have been ascribed to lower rates of adequate prenatal care, ${ }^{5}$ poor weight gain and nutrition, ${ }^{6}$ higher rates of tobacco use, high-risk health behaviors, ${ }^{7}$ and socioeconomic background characteristics. ${ }^{8}$

For the most part, teen pregnancy and childbearing studies refer to 15-19-year-old mothers and do not often include childbearing in adolescents $<15$ years old. Studies investigating specific adolescent age groups, comparing one group to another, often do not include the youngest adolescent mothers even though there is evidence suggesting that among the total population of teens, younger teens may be at higher risk for low birth weight and preterm delivery. 3,9,10

Infant mortality, defined as a death within the first year after a live birth, is the least frequently studied birth outcome because infant death is a relatively rare event. Most studies involving infants born to adolescent mothers have been limited in their analysis of infant mortality by sample size. Specifically, the risk for infant mortality in infants born to the youngest adolescent mothers is often obscured because of small sample size.

The marked increased risk for infant mortality in black populations compared with white populations across the childbearing age span is well documented. ${ }^{8}$ It is still unclear, however, whether risk differences exist among adolescents within specific maternal racial/ethnic groups. We do not know if the youngest mothers in different racial groups have the same risk for poor birth outcomes.

Investigations have also shown a difference between birth outcomes in Mexican American populations and non-Hispanic white populations. The risk for poor birth outcomes is lower among Mexican Americans when compared with whites. ${ }^{11,12}$ Still, we know little about the risk differences among adolescent age groups within the Mexican American population.

The role of men in adolescent childbearing and birth outcomes has received national attention. ${ }^{13,14}$ One study examining the impact of paternal involvement, defined as the father's identification on the birth certificate, found that the absence of the father's name was a potential risk factor for low birth weight and infant mortality in unmarried women of all ages. ${ }^{15}$ One potential theory to support using the father's name on the birth certificate as a marker for paternal involvement is that if a father is not willing to have his name put on the child's birth certificate, he may not be involved in the child's care. As teens were grouped as $<20$ years old in the studies involving paternity, we do not know if risk differences existed within the teen population.

Given that the rates of poor birth outcomes (low birth weight and preterm delivery) are higher in the youngest adolescent mothers, we hypothesize that children born to mothers $\leq 15$ years old are at greater risk for infant mortality compared with children born to older adolescent mothers. For our study, we evaluated the differences in the risks for infant mortality among adolescent age groups in the United States, specifically among $\leq 15$-year-olds, ${ }^{16}$ 16-17-year-olds, and 18-19-year-olds. We investigated the differences among these age groups within the three major U.S. racial/ethnic groups: non-Hispanic white, non-Hispanic black, and Mexican Americans. Because paternal involvement in childrearing may be a protective factor, we investigated the impact of missing information about the father of the infant as a possible risk marker for infant mortality.

\section{MATERIALS AND METHODS}

We combined the 1995 and 1996 comprehensive U.S. birth cohorts from the U.S. Department of Health and Human Services, Centers for Disease Control and Prevention and National Center for Health Statistics. These datasets include all births in the United States in 1995 and 1996 (approximately 4 million births per year). These datasets link infant death certificate information to respective birth certificates.

We limited our analysis to liveborn singleton, first births to mothers aged 12-19 years $(n=$ $777,762)$. Maternal age is a computed variable in this file. We excluded births to girls $\leq 11$ years old because they accounted for only 32 births in 1995 and 16 births in 1996. We excluded births at $<24$ weeks gestation and $<500 \mathrm{~g}$ because these fetuses have uncertain viability. We limited the dataset to singleton first births to avoid the potential confounding present with the known increased risk for poor birth outcomes associated with multiple 
births and second births to adolescents. ${ }^{17,18}$ In the data file, infant deaths are defined as deaths occurring any time within the first year after birth $(n=4631)$.

We assessed adequacy of prenatal care utilization using the R-GINDEX measure for prenatal care use, which takes into account the onset of prenatal care, number of prenatal visits, and gestational age at birth. ${ }^{19}$ In our analysis, we created an indicator variable that included inadequate prenatal care and no prenatal care together with a comparison made to adequate and intermediate prenatal care. Missing information regarding prenatal care was not included in the regression analysis (3\% of records). Self-reported tobacco use and alcohol use during pregnancy were analyzed as dichotomous variables (present compared to absent during pregnancy), with missing information excluded from the regression analysis $(18 \%$ of records with missing information on tobacco use and $14 \%$ with missing information on alcohol). The majority of missing information was from California (13.1\% of births in this dataset), which does not include information about tobacco and alcohol use on birth certificates. A smaller number of uniformly missing information was from South Dakota ( $0.2 \%$ of births), which does not include information on tobacco and alcohol use, and from Indiana $(2.4 \%$ of births), which does not include information about tobacco use. This needs to be considered when interpreting the adjusted analysis. Birth weight was analyzed as a continuous variable.

Father's age is an item on every birth certificate in the United States with variability in reporting rates. When the mother is married, the father is routinely reported on the birth certificate. In the majority of states (although the specific requirements vary), however, when the mother is single, the father must present himself and some form of identification in order to be reported on the birth certificate. Because the data base does not include information about the father's name for confidentiality, we used the reported father's age as a proxy for whether or not the father was acknowledged on the birth certificate. Information about the father's age correlated with other information about the father on the birth certificate, for example, race/ethnicity (Pearson correlation coefficient 0.9). Missing data for paternity was analyzed only for single mothers $(77 \%$ of the entire sample).

We used SAS version 6.12 for all analyses. We calculated infant mortality rates (IMR) along with their standard errors by maternal age and then performed an analysis of variance (ANOVA) general linear model procedure with the TukeyKramer adjustment for multiple comparisons to confirm previously established age group classifications. ${ }^{16}$ The following age group classification appears in the analysis: $\leq 15$ years old $(n=$ $76,262), 16-17$ years old $(n=268,817)$, and $18-19$ years old ( $n=432,683)$. The 18-19-year-old group was the reference age group for this analysis. After determining crude odds ratios (OR) for the entire cohort, we limited the dataset to the three largest U.S. racial/ethnic groups: non-Hispanic white $(n=375,290)$, non-Hispanic black $(n=$ 191,488), and Mexican American ( $n=129,736)$. We performed separate analyses for each of these three subgroups.

For the multivariable analysis, the primary outcome variable was infant mortality. We used logistic regression techniques to calculate adjusted ORs for maternal age categories. Our models included the following selected risk factors as well as interaction terms: race/ethnicity, inadequate prenatal care utilization, self-reported tobacco use, and self-reported alcohol use. Because the outcome of infant mortality is a relatively rare event, the adjusted ORs obtained from these models approximate adjusted relative risks (RR).

To determine the significance of acknowledged paternity, logistic regression analysis to evaluate the association of paternity acknowledgment with infant mortality was performed for single mothers by age group. The analysis was adjusted for maternal race/ethnicity, inadequate prenatal care utilization, and birth weight. We chose to control for birth weight in this analysis even though it is part of the causal pathway in an effort to determine if low birth weight would account for the excess risk for infant mortality associated with paternity acknowledgment in the youngest age group.

To determine risk factors within the $\leq 15$-yearold age group, we performed separate logistic regression analysis for possible risk factors associated with infant mortality. Inadequate prenatal care utilization using the GINDEX measure and no prenatal care were compared to the reference group of women with adequate or intermediate prenatal care utilization. Non-Hispanic black groups were compared with the non-Hispanic white reference group. Alcohol use and tobacco use during pregnancy were each compared with 
nonuse. For women who delivered at more than 36 gestational weeks, poor weight gain $(<20$ pounds) during pregnancy was compared with a reference group of weight gain of $\geq 20$ pounds during the pregnancy. The multivariable logistic regression for the $\leq 15$-year-old group alone included all these variables in addition to the paternity acknowledgment variable.

One statistical caveat: This dataset represents the entire, finite population of births in the United States for the years 1995 and 1996. Therefore, we can precisely determine the proportion of infants who did not survive the first year. However, in a finite population, this proportion is not necessarily the probability that an infant will not survive the first year in another time period. The proportion from the whole population in 1995 and 1996 serves as an estimate of the probability for other infants. As a result, confidence intervals (CIs) are necessary when we estimate an infant's risk of dying during the first year, but such (CIs) are not used when we describe the patterns of infant deaths for the specific population in our dataset.

\section{RESULTS}

For the years 1995 and 1996, early adolescent mothers have significantly higher rates of infant mortality compared with both older adolescent age groups for each of the three racial/ethnic groups (Table 1). Among the $\leq 15$-year-old group, there is a statistically significant difference $(p<$ 0.05 using ANOVA analysis) in IMR among all three racial/ethnic groups, with Mexican American infants having the lowest IMR and non-Hispanic whites having the highest rate. Among the 16-17-year-old age group, Mexican Americans have lower IMR compared with both non-Hispanic blacks and non-Hispanic whites. However, the rate for non-Hispanic blacks does not differ substantially from the rate for non-Hispanic whites in this age group. In the 18-19-year-old group, there are differences in IMR among the three groups, with Mexican Americans having the lowest rates and non-Hispanic blacks the highest.

Table 2 shows the crude and adjusted RRs associated with early adolescent childbearing. The crude RR for infant mortality associated with mothers $\leq 15$ years old is 1.56 (95\% CI 1.42, 1.71) and for mothers 16-17 years old is 1.19 (95\% CI $1.11,1.27)$ as compared with mothers $18-19$ years old. Stratifying for maternal factors, including race/ethnicity, alcohol use, tobacco use, and no prenatal care or inadequate prenatal care use, had very little impact on the overall RR.

When the three largest racial/ethnic groups were considered separately, the trends in risk for infant mortality among adolescent childbearing age groups resembled the trends noted in the entire birth cohort, although the magnitude of the risks differed between ethnic groups. Within the non-Hispanic white population, the risk for infant mortality among the $\leq 15$-year-old age group was $70 \%$ greater than the risk for the 18-19-yearold reference group. In the Mexican American population, the risk for the $\leq 15$-year-old group was almost $80 \%$ greater than the risk for the 18-19-year-old group. In the non-Hispanic black population, the risk for infant mortality associated with mothers $\leq 15$ years old was $35 \%$ as compared with mothers 18-19 years old in the reference group.

For those infants born to mothers $\leq 15$ years old, $62 \%$ of birth certificates did not contain information about the father. When the father's age

Table 1. Infant Mortality Rates per 1000 Live Births for Singleton, First Births in the United States, 1995-1996, by Maternal Age Group and Maternal Race/Ethnicity

\begin{tabular}{lcccc}
\hline & & Non-Hispanic & Non-Hispanic & Mexican \\
black & American \\
Age group & Full cohort & white & IMR & $\mathrm{n}=129,736$ \\
(years) & $\mathrm{IMR}$ & $\mathrm{IMR}$ & $\mathrm{n}=191,488$ & $\mathrm{n}$ \\
\hline$\leq 15$ & $\mathrm{n}=777,762$ & $\mathrm{n}=375,290$ & 8.4 & 4.2 \\
$16-17$ & 8.1 & 9.5 & 6.8 & 3.8 \\
$18-19$ & 6.3 & 6.9 & 6.5 & \\
\hline
\end{tabular}

ancludes all racial/ethnic groups in the United States (non-Hispanic white, non-Hispanic black, Mexican American, Puerto Rican, Cuban, Central/South American, other). $n=$ total number of births in 1995 and 1996. 
Table 2. Crude RR and Adjusted RR for Infant Mortality Associated with Maternal Age Groups, Stratified by Race/Ethnicity ${ }^{a}$

\begin{tabular}{|c|c|c|c|c|c|c|c|c|}
\hline \multirow[b]{2}{*}{$\begin{array}{l}\text { Age group } \\
\text { (years) }\end{array}$} & \multicolumn{2}{|c|}{ Full cohort } & \multicolumn{2}{|c|}{ Non-Hispanic white } & \multicolumn{2}{|c|}{ Non-Hispanic black } & \multicolumn{2}{|c|}{ Mexican American } \\
\hline & $\begin{array}{c}\text { Crude } \\
R R\end{array}$ & $\begin{array}{c}\text { Adjusted }^{\mathrm{b}} \\
R R\end{array}$ & $\begin{array}{c}\text { Crude } \\
R R\end{array}$ & $\begin{array}{c}\text { Adjusted }^{c} \\
\text { RR }\end{array}$ & $\begin{array}{c}\text { Crude } \\
R R\end{array}$ & $\begin{array}{c}\text { Adjusted }^{c} \\
\text { RR }\end{array}$ & $\begin{array}{c}\text { Crude } \\
R R\end{array}$ & $\begin{array}{c}\text { Adjusted } \\
R R\end{array}$ \\
\hline 15 & $\begin{array}{c}1.56 \\
(1.42,1.71)\end{array}$ & $\begin{array}{c}1.56 \\
(1.40,1.74)\end{array}$ & $\begin{array}{c}1.77 \\
(1.53,2.04)\end{array}$ & $\begin{array}{c}1.71 \\
(1.45,2.00)\end{array}$ & $\begin{array}{c}1.30 \\
(1.12,1.51)\end{array}$ & $\begin{array}{c}1.35 \\
(1.15,1.59)\end{array}$ & $\begin{array}{c}1.67 \\
(1.31,2.11)\end{array}$ & $\begin{array}{c}1.79 \\
(1.31,2.44)\end{array}$ \\
\hline-17 & $\begin{array}{c}1.19 \\
(1.11,1.27)\end{array}$ & $\begin{array}{c}1.19 \\
(1.10,1.28)\end{array}$ & $\begin{array}{c}1.29 \\
(1.18,1.40)\end{array}$ & $\begin{array}{c}1.26 \\
(1.15,1.39)\end{array}$ & $\begin{array}{c}1.05 \\
(0.94,1.19)\end{array}$ & $\begin{array}{c}1.06 \\
(0.93,1.21)\end{array}$ & $\begin{array}{c}1.09 \\
(0.91,1.31)\end{array}$ & $\begin{array}{c}1.17 \\
(0.92,1.50)\end{array}$ \\
\hline
\end{tabular}

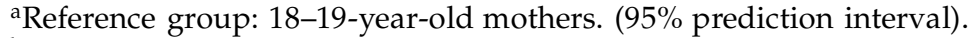

${ }^{b}$ Adjusted for race/ethnicity (non-Hispanic white, non-Hispanic black, and Mexican American), alcohol use, tobacco use, and no prenatal care/inadequate prenatal care utilization.

${ }^{\mathrm{c}}$ Adjusted for alcohol use, tobacco use, and inadequate prenatal care utilization.

was reported, 63\% were at least 3 years older and $29 \%$ were at least 5 years older than the young mother.

We investigated the possibility that there may be a systematic reporting bias on the birth certificates of infants born to the youngest mothers.
Figure 1 shows rates of missing data for selected variables in our dataset. The percent of fathers not reported for single mothers is much higher for the younger mothers. Nonreporting for other variables-tobacco use, alcohol use, prenatal care, and maternal education-have fairly stable

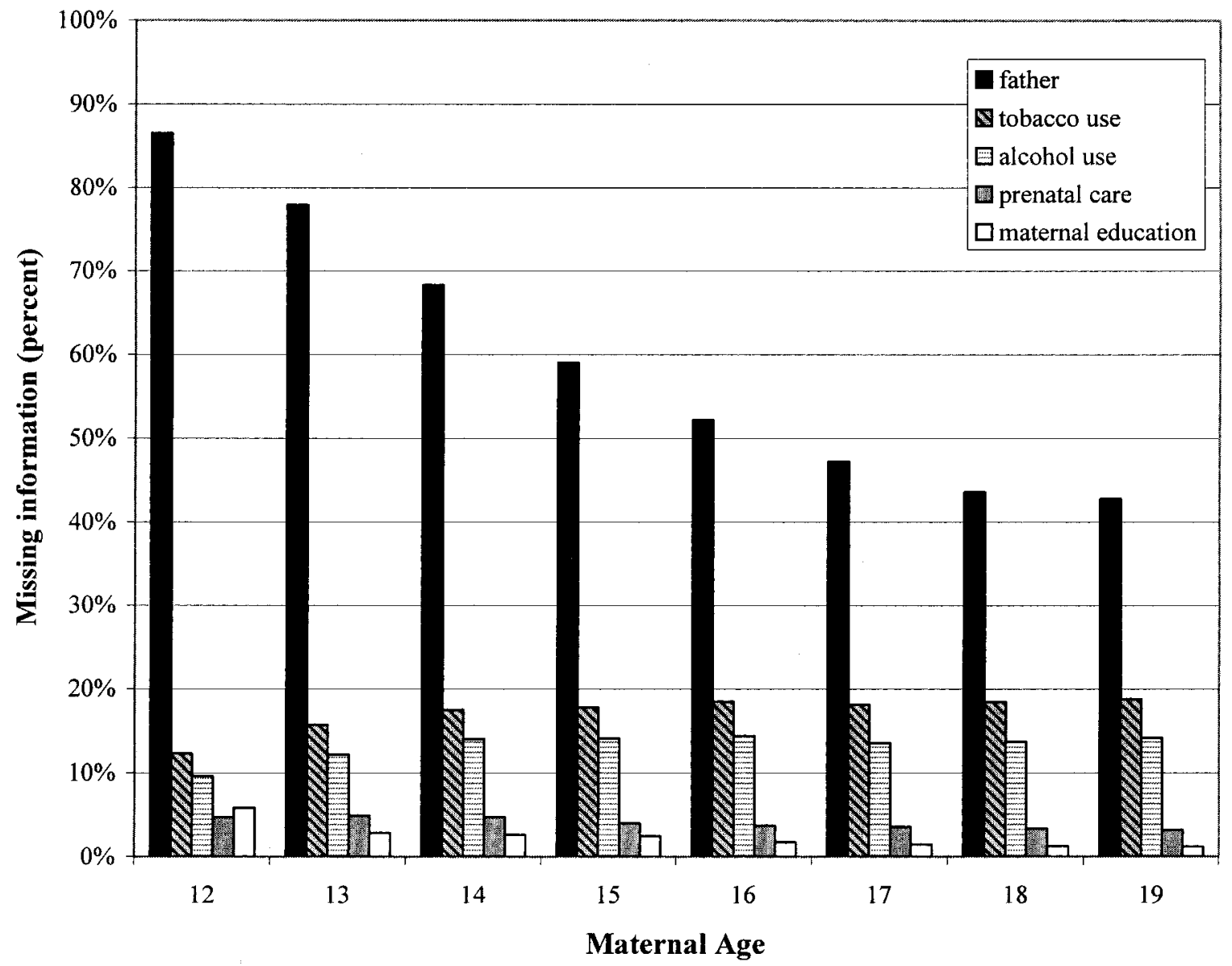

FIG. 1. Frequency of missing information on a birth certificate for specific items. (Frequency of missing information about the father of the infant was calculated for single mothers only.) 
rates of missing data across the age span, suggesting that the reporting bias is specific to paternity. Considering this marked difference in the frequency of missing information about fathers, not reporting the father was analyzed as a dichotomous risk factor variable in further analysis.

Not reporting the father on the birth certificate was associated with higher infant mortality for most groups (Table 3). Among all births in the $\leq 15$-year-old group, the adjusted RR for infant mortality associated with not reporting the father on the birth certificate was $24 \%$ greater compared with when the father was reported. The adjustments for no prenatal care or inadequate prenatal care and birth weight imply that there are other factors accounting for this increased risk for infant mortality that may be included in the marker for paternity acknowledgment. Findings were similar for 16-19-year-old mothers (therefore, the data are presented as an aggregate), with a $20 \%$ greater risk associated with not reporting the father on the birth certificate. In the $\leq 15$-yearold group, non-Hispanic white infants have the highest adjusted RR for infant mortality associated with not identifying the father on the birth certificate compared with non-Hispanic white mothers who report the father on the birth certificate. Mexican Americans in the youngest age group were found to have the lowest adjusted risk for infant mortality associated with paternity acknowledgment.

Early adolescent childbearing has been linked with many traditional risk factors associated with infant morbidity and mortality (Table 4). Within the $\leq 15$-year-old group, many of the listed risk factors have elevated unadjusted RRs when looked at as independent variables. However, when all these potential risk factors were put into the multivariable logistic model, only failure to report the father was found to be a significant risk marker for infant mortality.

\section{DISCUSSION}

Our results suggest that teens who bear children should not be considered as a single group, as is often the case when reporting statistical data or designing prevention programs. Based on the overall risk for infant mortality in singleton first births, our analysis suggests that when adolescent childbearing is evaluated as three separate age groups, $\leq 15$-year-olds, 16-17-year-olds, and 18-19-year-olds, there are marked differences among the groups. The risk for infant mortality associated with a child having a mother who is $\leq 15$ years old is $56 \%$ greater than if a mother is 18-19 years old. Children born to mothers 16-17 years old have intermediate outcomes.

Table 3. Relative Risk for Infant Mortality Associated with Not Reporting Father of Infant on Birth Certificate for Single Mothers ${ }^{\mathrm{a}}$

\begin{tabular}{lccc}
\hline & $\begin{array}{c}\text { Age group } \\
\text { (years) }\end{array}$ & $\begin{array}{c}\text { Crude RR } \\
(95 \% \mathrm{CI})\end{array}$ & $\begin{array}{c}\text { Adjusted RR } \\
(95 \% \text { CI }\end{array}$ \\
\hline Full cohort & $\leq 15$ & 1.32 & $1.24^{\mathrm{b}}$ \\
& & $(1.10,1.59)$ & $(1.02,1.51)$ \\
& $16-19$ & 1.33 & $1.20^{\mathrm{b}}$ \\
& & $(1.24,1.44)$ & $(1.11,1.30)$ \\
Non-Hispanic white & $\leq 15$ & 1.41 & $1.34^{\mathrm{c}}$ \\
& & $(1.05,1.89)$ & $(0.99,1.82)$ \\
& $16-19$ & 1.23 & $1.15^{\mathrm{c}}$ \\
Non-Hispanic black & $\leq 15$ & $(1.11,1.36)$ & $(1.03,1.27)$ \\
& & 1.15 & $1.02^{\mathrm{c}}$ \\
& $16-19$ & $(0.85,1.55)$ & $(0.75,1.39)$ \\
Mexican American & $\leq 15$ & $(1.18,1.53)$ & $1.25^{\mathrm{c}}$ \\
& & 1.55 & $(1.09,1.43)$ \\
& $16-19$ & $(1.01,2.39)$ & $0.86^{\mathrm{c}}$ \\
& & $(1.49$ & $(0.50,1.46)$ \\
& & $(1.18,1.88)$ & $1.35^{\mathrm{c}}$ \\
& & & $(1.05,1.74)$ \\
\hline
\end{tabular}

aReference group: father identified on the birth certificate for single mothers within specified age group.

${ }^{\mathrm{b}}$ Adjusted for maternal race/ethnicity, no care/inadequate prenatal care, and birth weight.

${ }^{c}$ Adjusted for inadequate prenatal care and birth weight. 
Table 4. RR for Infant Mortality Associated with Select Risk Factors within the $\leq 15$-Year-Old Age Group for 1995 and 1996 Birth Cohorts

\begin{tabular}{|c|c|c|}
\hline Risk factor & Reference group & Overall $R R$ \\
\hline $\begin{array}{l}\text { Father not identified } \\
\text { on birth certificate }\end{array}$ & $\begin{array}{l}\text { Father identified } \\
\text { on birth certificate }\end{array}$ & 1.32 \\
\hline $\begin{array}{l}\text { No care/inadequate } \\
\text { prenatal care utilization }\end{array}$ & $\begin{array}{l}\text { Adequate/moderate } \\
\text { prenatal care }\end{array}$ & 1.04 \\
\hline Non-Hispanic black & Non-Hispanic white & 0.89 \\
\hline Alcohol use & No alcohol use & 1.63 \\
\hline Tobacco use & No tobacco use & 1.48 \\
\hline $\begin{array}{l}\text { Pregnancy weight gain } \\
<20 \text { pounds }\end{array}$ & $\begin{array}{l}\text { Weight gain } \\
\geq 20 \text { pounds }\end{array}$ & 1.31 \\
\hline
\end{tabular}

When we stratified IMRs by the three largest U.S. race/ethnic groups, the decreasing IMRs with increasing age were parallel to each other. The IMRs for non-Hispanic whites, non-Hispanic blacks, and Mexican Americans were similar in the younger age groups. Consistent with previously published reports, however, notable differences appeared in rates among the 18-19-year olds ${ }^{10}$ with non-Hispanic black infants having the highest mortality rates. Previous populationbased analyses did not routinely break down IMRs by adolescent age subgroups. Therefore, the findings for the youngest teens are not as well known.

For Mexican Americans, the rates of infant mortality were lower in each age group compared with other U.S. populations. We could find no clear explanation for these findings. Other researchers have noted the lower rates of poor birth outcomes in Mexican Americans as compared with U.S. non-Hispanic whites and non-Hispanic blacks and have suggested several explanations: a protective social environment allowing adherence to traditional Mexican culture while in the United States, ${ }^{20}$ the healthy migrant theory-only healthy women cross the border to deliver their infants in the United States, an underreporting of Mexican American infant deaths on return to Mexico, and misclassification of Mexican ethnicity in U.S. vital statistics. ${ }^{21}$ The reason for the lower rates of infant mortality among the Mexican American population is a combination of many of these factors and other factors most likely to be explored.

In addition to IMRs, the RR for infant mortality associated with maternal age groups was also similar among racial/ethnic groups. Non-Hispanic white race was associated with the greatest risk for infant mortality in the $\leq 15$-year-old age group compared with 18-19-year-olds. The 16-17-year-old age group was also associated with an increased risk for infant mortality compared with the 18-19-year-old group. For both non-Hispanic blacks and Mexican Americans, however, only the $\leq 15$-year-old group was associated with an increased risk for infant mortality compared with the older group within that race/ethnicity. The lower $R R$ associated with the early adolescent group in non-Hispanic blacks may be explained by the overall elevated rates of infant mortality in the non-Hispanic black population. Thus, there is not as dramatic a difference in RR when comparing two maternal age groups within the non-Hispanic black population.

Fathers not identified on a significant number of birth certificates for single early adolescent mothers $(62 \%$ missing for those mothers $\leq 15$ years old) suggested the possibility that lack of paternity identification could be a risk marker for the increased risk of infant mortality in the youngest adolescent group. Within the $\leq 15$-yearold age group, the risk for infant mortality associated with not reporting the fathers, compared with when the father was reported, was elevated for all racial/ethnic groups. However, the risk was highest for infants born to non-Hispanic white early adolescent mothers.

Not reporting paternal age could represent an attempt to protect the fathers from social or legal consequences, although interpreting failure to identify the father on a birth certificate is difficult. This variable most likely incorporates a heterogeneous group of factors, and caution should be used when interpreting this as a marker for paternal involvement. The other factors it may represent include poor social support, statutory rape, expectation that the father will not be involved in child rearing, inability to identify the 
father, refusal by the father to take responsibility for the infant, or regulatory barriers imposed by the hospital or state. The requirements and barriers for acknowledging paternity vary by state. However, there are similarities among most states in that they require the assent of the father before the name may be added to the birth certificate. The prevalence of failure to identify the father of the infant varies among age groups and may reflect different social environments for women in each age group. Statutory rape and abusive relationships may have a role in these early adolescent pregnancies and perhaps infant mortality, as when fathers were reported, more than $60 \%$ would qualify for a statutory rape designation in 45 of the 51 United States and District of Columbia. ${ }^{22}$ Further investigation is needed to target the barriers to reporting fathers in this specific age group.

It is important for healthcare providers to determine why early adolescent childbearing is a high-risk condition. Biological immaturity ${ }^{3}$ does not tell the whole story. Some researchers have used biological immaturity to explain the higher rates of poor birth weight in younger teens. When we adjusted for birth weight in our analysis, however, the risk for infant mortality associated with failure to report the father was elevated. Part of the story may be domestic violence or physical abuse, as adolescents with poorer birth outcomes have a higher prevalence of physical abuse during pregnancy. ${ }^{23}$ The same social situation that predisposed the early adolescent to the risk of becoming pregnant may continue after the birth of the child if no intervention is provided. ${ }^{24}$ For example, Overpeck et al. ${ }^{25}$ reported that the earliest teen mothers, those $\leq 14$ years old, had more than a 6-fold increased risk for infant homicide compared with adults. ${ }^{25}$ That study suggested that the negative social influences that may have predisposed a young girl to have a child as an early adolescent may continue after the birth of the child.

The strengths of analyzing this database include the power to use infant mortality as a birth outcome rather than an intermediary determinant of poor birth outcomes, such as low birth weight or preterm delivery. A population-based cohort that includes all births in the United States for 2 years allowed us to make relevant comparisons among adolescent subgroups, including the three largest racial/ethnic groups in the United States. Because we were not using a sample, our measures of association for the dataset are absolute means for the population studied. Therefore, prediction intervals were used to determine potential variability in the point estimate for other birth cohort years.

Our study has several limitations. We were constrained by the information included in the vital statistics registry and, therefore, were not able to determine sociodemographic, financial, or personal information that may have affected birth outcomes. Although we did not measure a significant impact of prenatal care use on infant mortality, we did not have any measure of the content of prenatal care received. Consequently, it is difficult to know whether targeted interventions and support during the prenatal period would improve birth outcomes and maternal well-being. Given the substantial number of young teen mothers who receive inadequate or no prenatal care, attempts to remove barriers to prenatal care delivery may still be beneficial for this vulnerable population.

In light of our findings, it seems that the earliest teens, who have been relatively ignored in other analyses of teen childbearing, are at highest risk for poor birth outcomes. Whereas previous studies show that older teens, 18-19-years old, are at the same or lower risk for poor birth outcomes as adults, ${ }^{2,8}$ programs and policies have been directed at decreasing pregnancies and improving prenatal care in this older teen group. Studies should focus on the underlying causes of increased risk in the youngest mothers to more effectively direct programs and national policies that may improve conditions for both young mothers and their children.

\section{REFERENCES}

1. Battaglia FC, Frazier TM, Hellegers AE. Obstetric and pediatric complications of juvenile pregnancy. Pediatrics 1963;32:902.

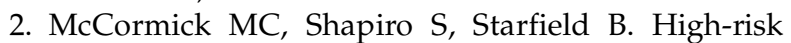
young mothers: Infant mortality and morbidity in four areas in the United States, 1973-1978. Am J Public Health 1984;74:18.

3. Fraser AM, Brockert JE, Ward RH. Association of young maternal age with adverse reproductive outcomes. N Engl J Med 1995;332:1113.

4. Miller HS, Lesser KB, Reed KL. Adolescence and very low birth weight infants: A disproportionate association. Obstet Gynecol 1996;87:83.

5. Wiemann CM, Berenson AB, Pino LG, McCombs SL. Factors associated with adolescents' risk for late entry into prenatal care. Fam Plann Perspect 1997;29:273. 
6. Scholl TO, Hediger ML, Ances IG, Belsky DH, Salmon RW. Weight gain during pregnancy in adolescence: Predictive ability of early weight gain. Obstet Gynecol 1990;75:948.

7. Cornelius MD, Taylor PM, Geva D, Day NL. Prenatal tobacco and marijuana use among adolescents: Effects on offspring gestational age, growth, and morphology. Pediatrics 1995;95:738.

8. Geronimus AT. The weathering hypothesis and the health of African-American women and infants: Evidence and speculations. Ethn Dis 1992;2:207.

9. Satin AJ, Leveno KJ, Sherman ML, Reedy NJ, Lowe TW, McIntire DD. Maternal youth and pregnancy outcomes: Middle school versus high school age groups compared with women beyond the teen years. Am J Obstet Gynecol 1994;171:184.

10. Cooper LG, Leland NL, Alexander G. Effect of maternal age on birth outcomes among young adolescents. Soc Biol 1995;42:22.

11. English PB, Kharrazi M, Guendelman S. Pregnancy outcomes and risk factors in Mexican Americans: The effect of language use and mother's birthplace. Ethn Dis 1997;7:229.

12. Fuentes-Afflick E, Hessol NA, Perez-Stable EJ. Testing the epidemiologic paradox of low birth weight in Latinos. Arch Pediatr Adolesc Med 1999;153:147.

13. Landry DJ, Forrest JD. How old are U.S. fathers? Fam Plann Perspect 1995;27:159, 165.

14. Taylor DJ, Chavez GF, Adams EJ, Chabra A, Shah RS. Demographic characteristics in adult paternity for first births to adolescents under 15 years of age. I Adolesc Health 1999;24:251.

15. Gaudino JA Jr, Jenkins B, Rochat RW. No fathers' names: A risk factor for infant mortality in the State of Georgia, USA. Soc Sci Med 1999;48:253.

16. Phipps MG, Sowers MF. Defining early adolescent childbearing. Am J Public Health 2002;92:125.
17. Luke B. The changing pattern of multiple births in the United States: Maternal and infant characteristics, 1973 and 1990. Obstet Gynecol 1994;84:101.

18. Hellerstedt WL, Pirie PL, Alexander GR. Adolescent parity and infant mortality, Minnesota, 1980 through 1988. Am J Public Health 1995;85:1139.

19. Alexander GR, Kotelchuck M. Quantifying the adequacy of prenatal care: A comparison of indices. Public Health Rep 1996;111:408.

20. James SA. Racial and ethnic differences in infant mortality and low birth weight: A psychosocial critique. Ann Epidemiol 1993;3:130.

21. Becerra JE, Hogue CJ, Atrash HK, Perez N. Infant mortality among Hispanics: A portrait of heterogeneity. JAMA 1991;265:217.

22. Donovan P. Can statutory rape laws be effective in preventing adolescent pregnancy? Fam Plann Perspect 1997;29:30, 40 .

23. Stevens-Simon C, McAnarney ER. Childhood victimization: Relationship to adolescent pregnancy outcome. Child Abuse Negl 1994;18:569.

24. Elders MJ, Albert AE. Adolescent pregnancy and sexual abuse. JAMA 1998;280:648.

25. Overpeck MD, Brenner RA, Trumble AC, Trifiletti LB, Berendes HW. Risk factors for infant homicide in the United States. N Engl J Med 1998;339:1211.

Address reprint requests to: Maureen G. Phipps, M.D., M.P.H. Brown Medical School Women $\mathcal{E}$ Infants Hospital of Rhode Island 101 Dudley Street Providence, RI 02905-2401

E-mail: mphipps@wihri.org 
This article has been cited by:

1. Emmanuel Ngui, Alicia Cortright, Kathleen Blair. 2008. An Investigation of Paternity Status and Other Factors Associated with Racial and Ethnic Disparities in Birth Outcomes in Milwaukee, Wisconsin. Maternal and Child Health Journal . [CrossRef]

2. Mary Breheny, Christine Stephens. 2006. Strengthening Social Support: Health Professionals' Views of the Health Care Needs of Adolescent Mothers. Australian Journal of Rehabilitation Counselling 12:2, 63-72. [CrossRef]

3. James Drife. 2004. Teenage pregnancy: a problem or what?. BJOG An International Journal of Obstetrics and Gynaecology 111:8, 763. [CrossRef] 